\title{
Magnetic Properties and Magnetocaloric Effect in Layered $\mathrm{NdMn}_{1.9} \mathrm{Ti}_{0.1} \mathrm{Si}_{2}$
}

\author{
M.F. Md Din ${ }^{1,4^{*}}$, J.L. Wang ${ }^{1,2}$, S.J. Kennedy ${ }^{2}$, S.J. Campbell ${ }^{3}$ and S.X. Dou ${ }^{1}$ \\ ${ }^{1}$ Institute of Superconducting and Electronic Material, University of Wollongong, Wollongong, NSW 2522, Australia \\ ${ }^{2}$ Bragg Institute, ANSTO, Lucas Heights, NSW 2234, Australia \\ ${ }^{3}$ School of Physical, Environmental and Mathematical Sciences, UNSW, Canberra, ACT 2600, Australia \\ ${ }^{4}$ Department Electric and Electronic Engineering, National Defence University of Malaysia, 57000 Kuala Lumpur, Malaysia
}

\section{ARTICLE INFO}

\section{Article history:}

Received 31 December 2013

Received in revised form 10 February 2014

Accepted 24 February 2014

Keywords:

Neutron diffraction

X-ray diffraction

Magnetocaloric effect

First order magnetic transition

Small hysteresis issue

\begin{abstract}
A B S T R A C T
The structural and magnetic properties of the $\mathrm{NdMn}_{1.9} \mathrm{Ti}_{0.1} \mathrm{Si}_{2}$ compund have been studied by high-intensity $\mathrm{x}$-ray and high-resolution neutron powder diffraction, specific heat, dc magnetization, and differential scanning calorimetry measurements over the temperature range of 3-450 K. The Curie temperature and Néel temperature of layered $\mathrm{NdMn}_{1.9} \mathrm{Ti}_{0.1} \mathrm{Si}_{2}$ are indicated as $\mathrm{T}_{\mathrm{C}} \sim 22 \mathrm{~K}$ and $\mathrm{T}_{\mathrm{N}} \sim 374 \mathrm{~K}$ respectively. The first order magnetic transition from antiferromagnetic [AFil-type] to ferromagnetic $[\mathrm{F}(\mathrm{Nd})+\mathrm{Fmc}]$ around $\mathrm{T}_{\mathrm{C}}$ is found in layered $\mathrm{NdMn}_{1.9} \mathrm{Ti}_{0.1} \mathrm{Si}_{2}$ and is associated with large magnetocaloric effect. This behavior has been confirmed as a contribution of the magnetostructural coupling by using neutron and $\mathrm{x}$-ray powder diffraction. The magnetic entropy change $-\Delta \mathrm{S}_{\mathrm{M}} \sim 15.3 \mathrm{~J} \mathrm{~kg}^{-1} \mathrm{~K}^{-1}$ and adiabatic temperature change $\Delta \mathrm{T}_{\mathrm{ad}} \sim 4.7 \mathrm{~K}$ have been determined using magnetization and specific heat measurement under $0-5 \mathrm{~T}$ applied fields. This compound exhibits almost no thermal and magnetic hysteresis, thus potentially applicable in low temperature region for magnetic refrigerator material.
\end{abstract}

\section{INTRODUCTION}

The magnetocaloric effect (MCE) has become an interesting area of research in the field of magnetic materials, with increasing prospects as the basis of magnetic cooling which potentially replaces conventional refrigeration systems over appropriate temperature regions [1-3]. Recently, magnetic materials with large MCE have been extensively studied experimentally and theoretically in order to produce suitable materials for actual applications [4-6]. First order magnetic phase transition materials appear to be promising candidates. However, normally such materials also exhibit large thermal and field hysteresis and temperature and magnetic field dependent magnetization. This behavior limits their usage in practical applications. Thus, the objective of our research is to find suitable new materials with large MCE which are free from any hystereses. Such compounds need further investigation, and it is important to understand their basic properties which contribute to their large MCE.

The ternary intermetallic compounds of the $\mathrm{RT}_{2} \mathrm{X}_{2}(\mathrm{R}=$ rare earth, $\mathrm{T}=$ transition metal, $\mathrm{X}=\mathrm{Si}$

${ }^{*}$ Corresponding author.

E-mail address: mfmd999@uowmail.edu.au or $\mathrm{Ge}$ ) family have attracted considerable attention due to their rich variety of interesting phenomena, including superconductivity, magnetism, mixed valence, heavy fermions, and Kondo behavior $[7,8]$. The $\mathrm{RT}_{2} \mathrm{X}_{2}$ compound form in the $\mathrm{ThCr}_{2} \mathrm{Si}_{2}$ structure (space group $14 / \mathrm{mmm}$ ), and the naturally layered nature of this crystal structure leads to an extreme sensitivity of the magnetic order to the interatomic distances [9].

Here, we present a detailed investigation of the influence of replacing $\mathrm{Mn}$ atoms by $\mathrm{Ti}$ atoms on the magnetic structure and magnetic phase transition in $\mathrm{NdMn}_{2-\mathrm{x}} \mathrm{Ti}_{\mathrm{x}} \mathrm{Si}_{2}$ compounds $\left(\mathrm{NdMn}_{1.9} \mathrm{Ti}_{0.1} \mathrm{Si}_{2}\right)$. The main interest is to explore the effects of replacing $\mathrm{Mn}$ atoms of atomic radius $\mathrm{r}(\mathrm{Mn})=1.35$ $\AA$ and electronic configuration $\mathrm{Mn}\left(3 d^{5} 4 s^{2}\right)$ with the larger $\mathrm{Ti}$ atoms of atomic radius $\mathrm{r}(\mathrm{Ti})=1.45 \AA$ and electron configuration $\mathrm{Ti}\left(3 d^{2} 4 s^{2}\right)$. In the case of $\mathrm{NdMn}_{2-\mathrm{x}} \mathrm{Co}_{\mathrm{x}} \mathrm{Si}_{2}$ [10] for example, replacement of $\mathrm{Mn}$ by the smaller Co atoms, $\mathrm{r}(\mathrm{Co})=1.25 \AA$ of electronic configuration Co $\left(3 d^{7} 4 s^{2}\right)$, leads to a decrease in magnetic entropy change from $\sim 14.4 \mathrm{~J}$ $\mathrm{kg}^{-1} \mathrm{~K}^{-1}$ with $\mathrm{x}=0.2$ to $12.4 \mathrm{~J} \mathrm{~kg}^{-1} \mathrm{~K}^{-1}$ with $\mathrm{x}=0.4$ $(\Delta \mathrm{B}=0-5 \mathrm{~T})$ but the Curie temperature $\mathrm{T}_{\mathrm{C}} \sim 45 \mathrm{~K}$ does not change with $(\mathrm{x}=0.2,0.4,0.8$ and 1$)$. In this study, we will explore the effects of Ti substitution for $\mathrm{Mn}$ in the $\mathrm{NdMn}_{2} \mathrm{Si}_{2}$ compound on the structural and magnetic properties, as the substitution is 
expected to increase the distance between magnetic atoms, thus modifying the magnetic states of both the $\mathrm{Nd}$ and the Mn-sublattices.

\section{EXPERIMENTAL METHODS}

The layered $\mathrm{NdMn}_{1.9} \mathrm{Ti}_{0.1} \mathrm{Si}_{2}$ was prepared by arc melting. It was subsequently annealed at $900^{\circ} \mathrm{C}$ for one week in an evacuated quartz tube to improve the crystallization of the sample [11] and then quenched in water. The crystal structure of the sample was checked by room temperature powder $\mathrm{x}$-ray diffraction (XRD) measurements using $\mathrm{CuK}_{\alpha 1}$ radiation with the diffraction patterns refined using the Fullprof software package [12]. The magnetic behavior and transitions were investigated by superconducting quantum interference device $(10-300 \mathrm{~K})$ and differential scanning calorimetry (DSC) $(300-450 \quad \mathrm{~K})$ measurements. The crystallographic and magnetic structural behaviors of the layered $\mathrm{NdMn}_{1.9} \mathrm{Ti}_{0.1} \mathrm{Si}_{2}$ sample were investigated over the temperature range of $3-450 \mathrm{~K}$ by powder neutron diffraction experiments using the Echidna high resolution powder diffractometer (wavelength $\lambda=1.622(1) \AA$ ) at the Open Pool Australian Light Water Reactor (OPAL), Lucas Heights, Australia and the high intensity $\mathrm{x}$-ray powder diffractometer (wavelength $\lambda=0.688(1) \AA$ ) at the Australian Synchrotron.

\section{RESULTS AND DISCUSSION}

The room temperature $\mathrm{x}$-ray diffraction (XRD) data at Fig. 1 shows that layered $\mathrm{NdMn}_{1.9} \mathrm{Ti}_{0.1} \mathrm{Si}_{2}$ crystallize in the $\mathrm{ThCr}_{2} \mathrm{Si}_{2}$ type structure with space group I4/mmm [13]. The measured data from the diffraction patterns were analysed using the Rietveld refinement technique [12]. It was found that the substitution of Ti for Mn does not change the crystal structure but leads to an expansion of the unit cell compared with pure $\mathrm{NdMn}_{2} \mathrm{Si}_{2}[22,28]$. The lattice constants $a=4.0088$ (5) $\AA$ and $c=10.557$ (5) $\AA$, and correspondingly the unit cell volumes $\mathrm{V}=169.66$ (8) $\AA^{3}$, were found to increase with the Ti content consistent with the larger atomic radius of $\mathrm{Ti}$ compared to $\mathrm{Mn}$.

The temperature dependence of the magnetization of $\mathrm{NdMn}_{1.9} \mathrm{Ti}_{0.1} \mathrm{Si}_{2}$ was measured in a magnetic field of $\mathrm{B}=0.01 \mathrm{~T}$ over the $10-300 \mathrm{~K}$ temperature range. The result is shown in Fig. 2 together with the differential scanning calorimetry (DSC) curves over the 300-450 K temperature range. The value of the Néel temperature $T_{N} \sim 374 \mathrm{~K}$ and the Curie temperature $\mathrm{T}_{\mathrm{C}} \sim 22 \mathrm{~K}$, for the compound, as defined by $1 / \mathrm{M}$ versus temperature and the maxima of the $d \mathrm{M} / d \mathrm{~T}$ versus temperature graphs, respectively (inset to Fig. 2). For the DSC measurements, the phase transition temperatures were determined by the maxima of the DSC signals. Comparison of results obtained under otherwise identical conditions for cooling and warming revealed no thermal hysteresis.

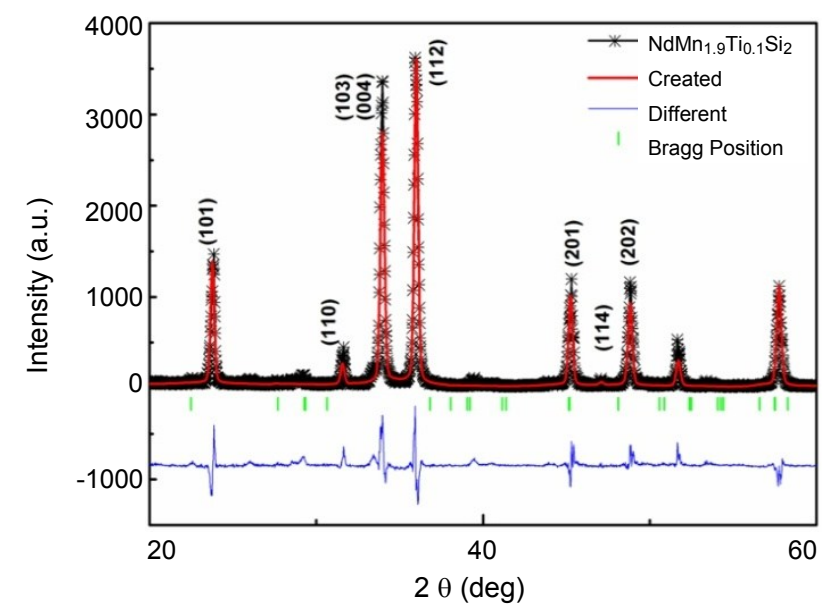

Fig. 1. X-ray diffraction pattern of the $\mathrm{NdMn}_{1.9} \mathrm{Ti}_{0.1} \mathrm{Si}_{2}$ compound at room temperature.

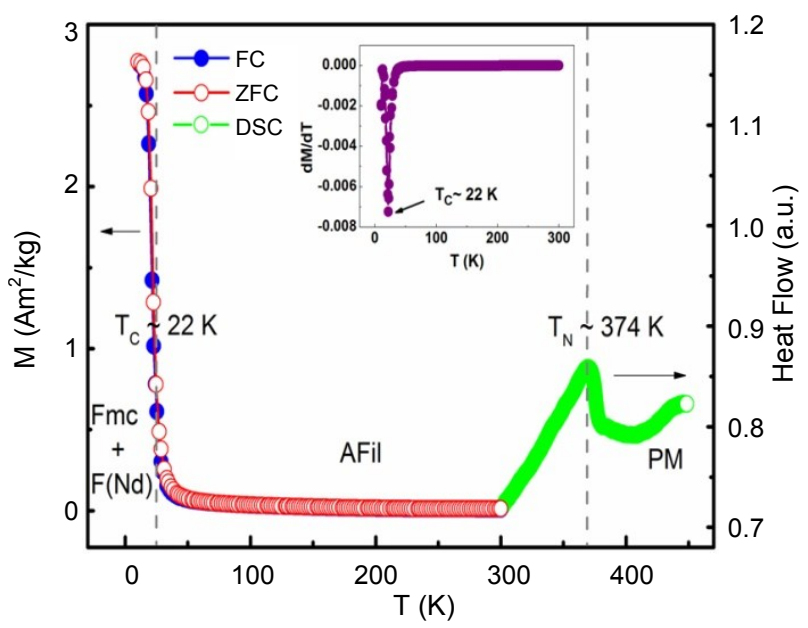

Fig. 2. Temperature dependence of magnetization of $\mathrm{NdMn}_{1.9} \mathrm{Ti}_{0.1} \mathrm{Si}_{2}$ as measured in a field of $0.01 \mathrm{~T}$ (left axis; red symbols for zero field cooling, ZFC, and blue symbol for field cooling, FC); and differential scanning calorimetry measurements for the $300-450 \mathrm{~K}$ temperature range (right axis; solid green symbols). The value of TC is defined from $d \mathrm{M} / d \mathrm{~T}$ (inset).

The substitution of $\mathrm{Ti}$ in $\mathrm{NdMn}_{2} \mathrm{Si}_{2}$ is also expected to weaken the exchange interactions of $\mathrm{Mn}-\mathrm{Mn}$ between layers and the Mn-Nd due to the magnetic dilution effect. Moreover, the change in electronic environment from replacing $\mathrm{Mn}\left(3 d^{5} 4 s^{2}\right)$ by $\mathrm{Ti}\left(3 d^{2} 4 s^{2}\right)$ is also expected to influence the magnetic structures and states of the $\mathrm{NdMn}_{2-\mathrm{x}} \mathrm{Ti}_{\mathrm{x}} \mathrm{Si}_{2}$ compounds as confirmed by another study [14]. This is supported by Density Functional Theory calculations for $\mathrm{RMn}_{2} \mathrm{Ge}_{2}(\mathrm{R}=\mathrm{Y}$ or $\mathrm{Ca})$ compounds [15] which indicate that to a large extent, the 
magnetic moment is determined mainly by the $\mathrm{Mn}-\mathrm{Mn}$ interatomic distances, while the interstitial electron density contributes to the change in magnetic structures, as have been confirmed by neutron diffraction analysis [14].

Basically, giant MCE values and magnetic entropy changes are usually obtained with a first order magnetic transition due to a large rate of change of magnetization compared with materials that exhibit a second order transition. The magnetization curves for $\mathrm{NdMn}_{1.9} \mathrm{Ti}_{0.1} \mathrm{Si}_{2}$ for fields in the 0-5 $\mathrm{T}$ range around their ferromagnetic ordering temperatures show almost no magnetic hysteresis and very small hysteresis loss around $0.8 \mathrm{~J} \mathrm{~kg}^{-1}$ as defined from another reference [14], indicating the advantage of this material for real application. Furthermore, the Arrott plots are found to be $S$-shaped near $\mathrm{T}_{\mathrm{C}}$; this indicates a negative order of the sign of the coefficient $\mathrm{c} 2(\mathrm{~T})$ in the Landau expansion of the magnetic free energy [16], thereby denoting a first order magnetic transition.

The magnetic entropy change, $-\Delta \mathrm{S}_{\mathrm{M}}$, has been determined for the $\mathrm{NdMn}_{1.9} \mathrm{Ti}_{0.1} \mathrm{Si}_{2}$ compound from the magnetization curves for both increasing and decreasing field strengths as functions of temperature and magnetic field $(\Delta \mathrm{B}=0-5 \mathrm{~T})$ as shown in Fig. 3. The magnetic entropy change has been derived by applying the standard Maxwell relation [17]:

$$
\Delta S_{M}(T, B)=\int_{0}^{B}\left(\frac{\partial M}{\partial T}\right)_{B} d B
$$

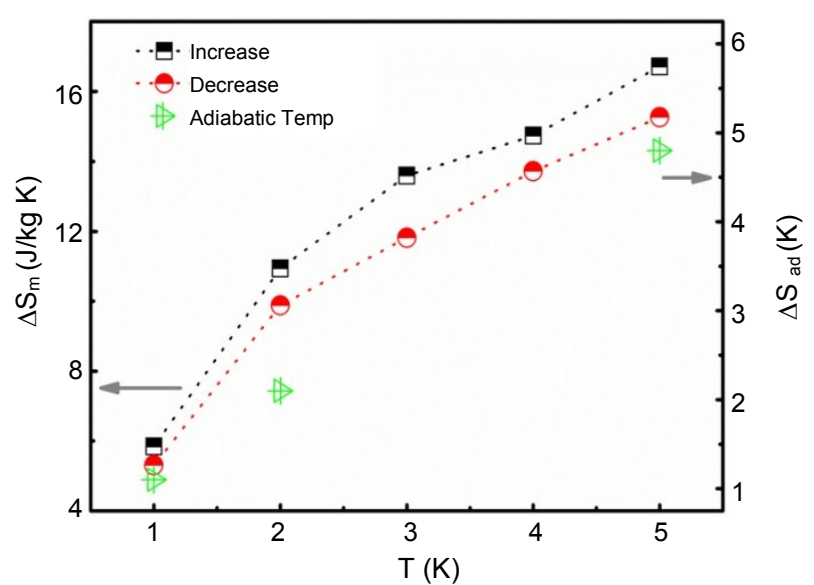

Fig. 3. Magnetic entropy change values of $\mathrm{NdMn}_{1.9} \mathrm{Ti}_{0.1} \mathrm{Si}_{2}$ as measured in a field of 0-5 $\mathrm{T}$ (left axis; red symbols for decrease and black symbol for increase field); and adiabatic temperature values of $\mathrm{NdMn}_{1.9} \mathrm{Ti}_{0.1} \mathrm{Si}_{2}$ as measured in fields of 0,2 , and $5 \mathrm{~T}$ (right axis; green symbols).

As shown in Fig. 3, the $-\Delta \mathrm{S}_{\mathrm{M}}$ values (from increasing and decreasing field) have a small different respectively. The changes in magnetic entropy for $\mathrm{NdMn}_{1.9} \mathrm{Ti}_{0.1} \mathrm{Si}_{2}$ ferromagnetic ordering temperatures are indicated in this paper as calculated from decreasing applied fields in order to satisfy the suitability of different experimental and related analytical approaches to establish the isothermal entropy change [18].The entropy values at the Curie temperature are $-\Delta \mathrm{S}_{\mathrm{M}} \sim 15.3 \mathrm{~J} \mathrm{~kg}^{-1} \mathrm{~K}^{-1}$ $(\Delta \mathrm{B}=0-5 \mathrm{~T})$ and $-\Delta \mathrm{S}_{\mathrm{M}} \sim 9.8 \mathrm{~J} \mathrm{~kg}^{-1} \mathrm{~K}^{-1}(\Delta \mathrm{B}=0-2 \mathrm{~T})$ at $\mathrm{T}_{\mathrm{C}} \sim 22 \mathrm{~K}$ respectively. Nevertheless it is noted that the MCE values of $-\Delta \mathrm{S}_{\mathrm{M}} \sim 15.3 \mathrm{~J} \mathrm{~kg}^{-1} \mathrm{~K}^{-1}$ for $\mathrm{NdMn}_{1.9} \mathrm{Ti}_{0.1} \mathrm{Si}_{2}$ at $0-5 \mathrm{~T}$ applied field is comparable with MCE values for other materials $[19,20]$ in the temperature region below $100 \mathrm{~K}$; particularly important is the very small field hysteresis losses of the compound.

The magnetic entropy change, $-\Delta \mathrm{S}_{\mathrm{M}}(T, B)$, has also been derived from heat calorimetric measurements of the field dependence of heat capacity using the following expression $[2,21,22]$ :

$$
-\Delta S_{M}(T, B)=\int_{0}^{T}\left(\frac{C(T, B)-C(T, 0)}{T}\right) d T
$$

where $C(T, B)$ and $C(T, 0)$ are the values of the heat capacity measured in field $B$ and zero field, respectively. The corresponding adiabatic temperature change, $\Delta T_{a d}$ can be evaluated from $\Delta S_{M}(T, B)$ and the zero field heat capacity data as:

$$
\Delta T_{a d}(T, B)=\int_{0}^{B} \frac{T}{C_{B, P}}\left(\frac{\partial M}{\partial T}\right)_{B} d B
$$

The $\Delta T_{\mathrm{ad}}$ values are calculated from the set of heat capacity measurement obtained for $\mathrm{NdMn}_{1.9} \mathrm{Ti}_{0.1} \mathrm{Si}_{2}$ with $\mathrm{B}=0,2$ and $5 \mathrm{~T}$. The corresponding $\Delta T_{\text {ad }}$ values are shown in Fig. 3 (left side). The peak value of the adiabatic temperature change is $\Delta T_{a d}^{\max } \sim 4.7 \mathrm{~K}$ for $\Delta B=0-5 \mathrm{~T}$. As shown in Fig. 3, the maximum magnetic entropy change for $\mathrm{NdMn}_{1.9} \mathrm{Ti}_{0.1} \mathrm{Si}_{2}$ as determined from magnetic measurements using the Maxwell relation, namely $-\Delta \mathrm{S}_{\mathrm{M}}{ }^{\max } \sim 15.3 \mathrm{~J} \mathrm{~kg}^{-1} \mathrm{~K}^{-1}$ and $9.8 \mathrm{~J} \mathrm{~kg}^{-1} \mathrm{~K}^{-1}$ for $\Delta B=0-5 \mathrm{~T}$ and $0-2 \mathrm{~T}$, are comparable to the maximum entropy change $-\Delta \mathrm{S}_{\mathrm{M}}{ }^{\max } \sim 15 \mathrm{~J} \mathrm{~kg}^{-1} \mathrm{~K}^{-1}$ and $9.3 \mathrm{~J} \mathrm{~kg}^{-1} \mathrm{~K}^{-1}$ as determined from the heat capacity measurement [14]. The good agreement between the two sets of measurements confirms that the $-\Delta \mathrm{S}_{\mathrm{M}}$ values derived for $\mathrm{NdMn}_{1.9} \mathrm{Ti}_{0.1} \mathrm{Si}_{2}$ from the magnetization measurements represent the MCE behaviour within experimental errors $[4,5,23]$.

As shown by the series of $\mathrm{x}$-ray diffraction patterns in Fig. 4, the $\mathrm{NdMn}_{1.9} \mathrm{Ti}_{0.1} \mathrm{Si}_{2}$ compound is single phase and exhibits the body centered tetragonal $\mathrm{ThCr}_{2} \mathrm{Si}_{2}$-type structure (space group $I 4 / \mathrm{mmm}$ ) over the temperature range $\sim 10-300 \mathrm{~K}$. No change in crystal structure is observed over this temperature range although, as discussed below, the $a$ lattice parameter is found to increase slightly around $\mathrm{T}_{\mathrm{C}} \sim 22 \mathrm{~K}$ while the $c$ lattice parameter decreases. The patterns have been analysed using the Fullprof [12] software, and the changes in 
lattices parameters $a$ and $c$ around $\mathrm{T}_{\mathrm{C}}$ (as volume change $\Delta \mathrm{V} / \mathrm{V} \sim 0.4 \%$ ) was found to agree well with the neutron data as discussed below. The x-ray diffraction analysis result in Fig. 4 (inset) together with coexistence of two phases (AFil and Fmc + F (Nd) phases) across magnetic transition indicate first order magnetic behaviour.

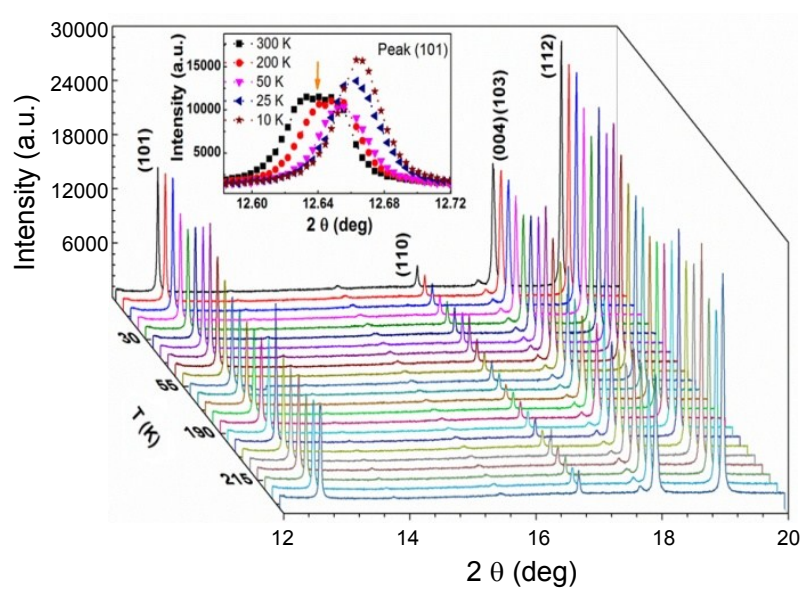

Fig. 4. X-ray diffraction patterns of $\mathrm{NdMn}_{1.9} \mathrm{Ti}_{0.1} \mathrm{Si}_{2}$ over the temperature range $\mathrm{T}=10-300 \mathrm{~K}(\lambda=0.8265(8) \AA)$; and coexistence behaviour of two phases AFil and Fmc $+\mathrm{F}(\mathrm{Nd})$ phases as indicated by the arrow (inset).

The $\mathrm{NdMn}_{1.9} \mathrm{Ti}_{0.1} \mathrm{Si}_{2} \quad$ compound was investigated by neutron diffraction measurements over the $3-450 \mathrm{~K}$ temperature range as the aims of the work were to determine the magnetic structures and to explore structural changes at the transition temperatures. The diffraction patterns $(\lambda=1.622$ (1) $\AA)$ and Rietveld refinements obtained for $\mathrm{NdMn}_{1.9} \mathrm{Ti}_{0.1} \mathrm{Si}_{2}$ at $450 \mathrm{~K}, 100 \mathrm{~K}$ and $3 \mathrm{~K}$ are shown in Fig. 5(a-c) respectively. The selected temperatures typify the behavior of $\mathrm{NdMn}_{1.9} \mathrm{Ti}_{0.1} \mathrm{Si}_{2}$ in the three magnetic regions (paramagneticantiferromagnetic-ferromagnetic) as indicated from the magnetization and DSC measurements of Fig. 1. Rietveld refinements of the neutron diffraction pattern at $450 \mathrm{~K}$ (Fig. 5(a)) confirm that $\mathrm{NdMn}_{1.9} \mathrm{Ti}_{0.1} \mathrm{Si}_{2}$ has the $\mathrm{ThCr}_{2} \mathrm{Si}_{2}$ structure as expected. The absence of magnetic scattering above $\mathrm{T}_{\mathrm{N}} \sim 374 \mathrm{~K}$ in reflections such as (101), (111) and (112) is consistent with a paramagnetic (PM) state. (cf. e.g. the disordered magnetic states (PM) observed in similar materials $[11,24,25])$. $\mathrm{NdMn}_{1.9} \mathrm{Ti}_{0.1} \mathrm{Si}_{2}$ is found to exhibit the antiferromagnetic interlayer coupling structure (AFil) down to $\mathrm{T}_{\mathrm{C}} \sim 22 \mathrm{~K}$ (see e.g. the $100 \mathrm{~K}$ pattern of Fig. 5(b)) below $\mathrm{T}_{\mathrm{N}} \sim 374 \mathrm{~K}$. The AFil structure a collinear antiferromagnetic structure between adjacent Mn planes in $\mathrm{a}+-+-$ sequence along the $c$ axis - is indicated by the magnetic scattering observed at the (111), (113) and (201) reflections; (extinction rules $h+k=2 n$ and $h+k+l=2 n+1)$ in agreement with Dincer et al [25]. Furthermore, the absence of magnetic scattering from the (111), (113) and (201) reflections at $3 \mathrm{~K}$ in Fig. 5(c), combined with the increase in intensity of the (112) and (101) peaks, indicate that the interlayer spin components of the Mn moments align parallelly, thus leading to a canted ferromagnetic structure $(\mathrm{F} m c)$ for the Mn sublattice. The presence of the purely magnetic peak (001) below $\mathrm{T}_{\mathrm{C}}$ indicates the existence of antiferromagnetic component of $\mathrm{Mn}$ moment in the $a b$-plane [26]. At lower temperatures (e.g. $3 \mathrm{~K}$; Fig. 5(c)), the increase in the intensities of the (112) (contributions from both $\mathrm{Nd}$ and Mn-sublattices) and (101) (contribution only from Nd-sublattice [26]) reflections further indicate an additional contribution from $\mathrm{Nd}$ moments coupled parallel to the $\mathrm{Mn}$ moments along $c$-axis, thereby leading to the formation of $\mathrm{F} m c+\mathrm{F}(\mathrm{Nd})$ magnetic structure as depicted in Fig. 6. This behavior agrees well with the results of Welter et al. [27] who demonstrated that in the $\mathrm{RMn}_{2} \mathrm{Ge}_{2}$ compounds with $\mathrm{R}=\operatorname{Pr}$ and $\mathrm{Nd}$, rare earth moments ferromagnetically coupled with the Mn sublattice at low temperatures. This behavior, also applicable to $\mathrm{NdMn}_{2} \mathrm{Si}_{2}$ [26] and $\mathrm{NdMn}_{2} \mathrm{Si}_{1.6} \mathrm{Ge}_{0.4}$ [5] compounds, is due to the exchange interaction between the light rare earth elements and $3 d$ transition metal as reported by Coey [28]. Ordering of the $\mathrm{Nd}$ sublattice in $\mathrm{NdMn}_{2} \mathrm{Si}_{2}$ below $\mathrm{T}_{\mathrm{C}}$ has also been confirmed by Chatterji et. al [29] from inelastic neutron scattering.

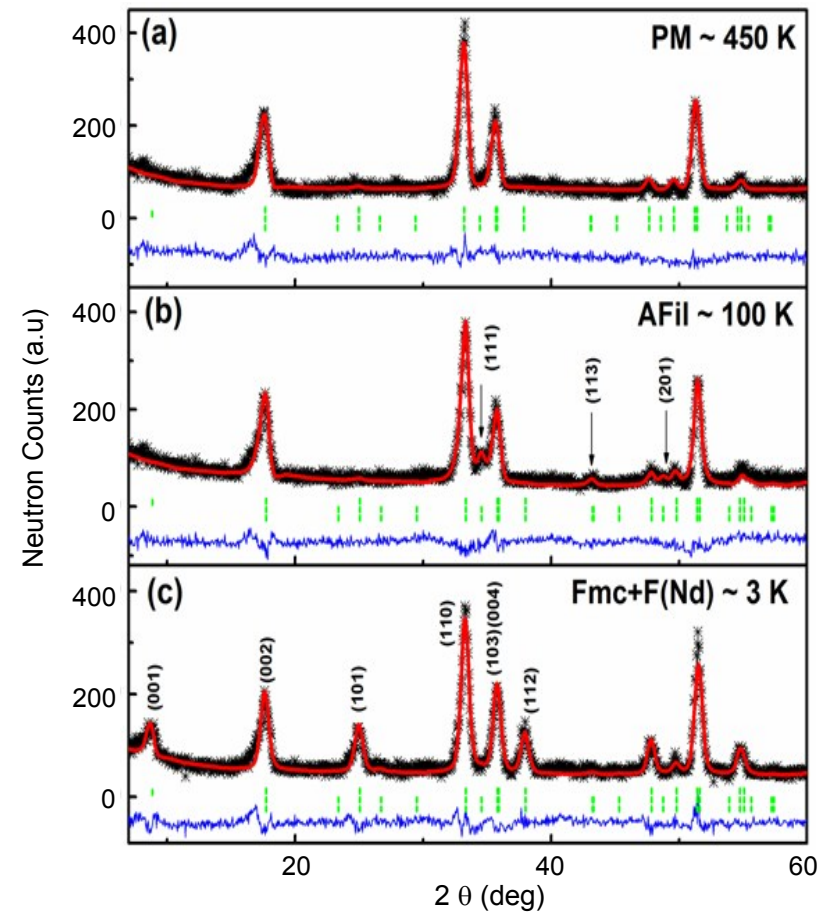

Fig. 5. Neutron diffraction patterns for $\mathrm{NdMn}_{1.9} \mathrm{Ti}_{0.1} \mathrm{Si}_{2}$ at 450 $\mathrm{K}, 100 \mathrm{~K}$, and $3 \mathrm{~K}$, respectively. The star symbols represent the observed patterns and the red solid lines the refined patterns. The blue lines represent the differences between the observed and refined patterns; the vertical bars indicate the Bragg peak positions for the nuclear (top), Fmc magnetic (middle) and AFil magnetic (bottom) structure respectively. 
The variation in the $a$ and $c$ lattice parameters with temperature are plotted in Fig. 6. Both the $a$ and $c$ values exhibit a monotonic decrease with temperature in the region of the antiferromagnetic transition between $\mathrm{T}_{\mathrm{N}} \sim 374 \mathrm{~K}$ and $\mathrm{T}_{\mathrm{C}} \sim 22 \mathrm{~K}$, while below $\mathrm{T}_{\mathrm{C}} \sim 22 \mathrm{~K}$, the $a$ lattice parameter expands slightly from $3.998 \AA$ at $35 \mathrm{~K}$ to $4.001 \AA$ at $3 \mathrm{~K}$ whereas the $c$ lattice parameter decreases from $10.536 \AA$ at $35 \mathrm{~K}$ to $10.523 \AA$ at $3 \mathrm{~K}$. The variation in lattice parameters $a$ and $c$ shown in Fig. 6 for the $\mathrm{PM}, \mathrm{AF} i l$, and $\mathrm{F} m c+\mathrm{F}(\mathrm{Nd})$ states is comparable and agree well with $\mathrm{x}$-ray diffraction patterns. The changes in lattice parameter at $\mathrm{T}_{\mathrm{C}} \sim 22 \mathrm{~K}$, when the magnetic state changes from AFil to $\mathrm{F} m c+\mathrm{F}(\mathrm{Nd})$ structure, indicates the presence of strong magnetostructural coupling around $\mathrm{T}_{\mathrm{C}}$. As discussed recently $[8,30]$, the strong magnetostructural coupling leads to a large structural entropy change around the magnetic phase transition, thereby contributing to the total entropy change around $\mathrm{T}_{\mathrm{C}}$. The contribution of the structure's volume expansion effects to the MCE value for $\Delta B=0-5 \mathrm{~T}$ is found to be $-\Delta S_{\text {structural }} \sim 1.25 \mathrm{~J} \mathrm{~kg}^{-1} \mathrm{~K}^{-1}$ as estimated using the method from K. A. Gschneidner et al. [30].

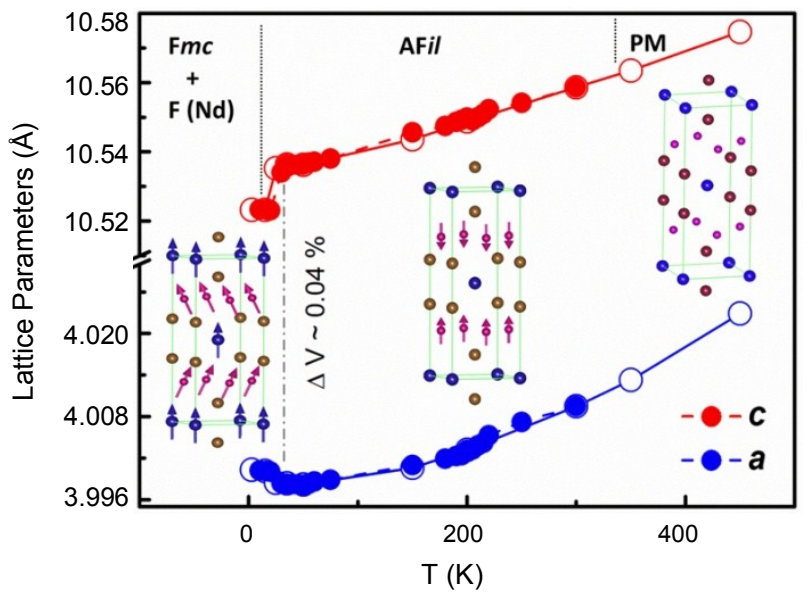

Fig. 6. The lattice parameters of $\mathrm{NdMn}_{1.9} \mathrm{Ti}_{0.1} \mathrm{Si}_{2}$ as a function of temperature defined from neutron (open symbols) and x-ray (closed symbols) diffraction pattern; magnetic structure for $\mathrm{F} m c+\mathrm{F}(\mathrm{Nd})$-type below and AFil-type above $\mathrm{T}_{\mathrm{C}}$ as shown together in the figure include percentage of volume change.

\section{CONCLUSION}

A systematic investigation of the structural and magnetic characteristics of the $\mathrm{NdMn}_{1.9} \mathrm{Ti}_{0.1} \mathrm{Si}_{2}$ compound has been carried out. Substitution of Ti for $\mathrm{Mn}$ leads to decreases in the Curie temperature and the Néel temperature from $\mathrm{T}_{\mathrm{C}} \sim 36 \mathrm{~K}$ and $\mathrm{T}_{\mathrm{N}} \sim$ $380 \mathrm{~K}$ for $\mathrm{NdMn}_{2} \mathrm{Si}_{2}$ to $\mathrm{T}_{\mathrm{C}} \sim 22 \mathrm{~K}$ and $\mathrm{T}_{\mathrm{N}} \sim 374 \mathrm{~K}$. A metamagnetic transition from the antiferromagnetic (AFil-type) to the ferromagnetic state due to the application of magnetic field was observed above $T_{C}$ for the $\mathrm{NdMn}_{1.9} \mathrm{Ti}_{0.1} \mathrm{Si}_{2}$ compound. Substitution of Mn by Ti leads to a small reduction of the magnetic entropy change. However, analysis of the magnetization data demonstrates that the first order magnetic transition of $\mathrm{NdMn}_{2} \mathrm{Si}_{2}$ around $\mathrm{T}_{\mathrm{C}}$ remains unchanged on replacement of Mn by $\mathrm{Ti}(\mathrm{x}=0.1)$, and this substitution eliminates the thermal hysteresis and significantly reduces the magnetic hysteresis loss, thus providing a promising material for magnetic refrigerator application.

\section{ACKNOWLEDGMENT}

This work was supported in part by a grant from Australian Research Council's Discovery Projects (DP0879070; DP110102386). M. F Md Din acknowledges the Malaysian Ministry of Higher Education for a $\mathrm{PhD}$ scholarship.

\section{REFERENCES}

1. J. Glanz, Making a Bigger Chill With Magnets, Science 279 (1998) 2045.

2. K.A. Gschneidner Jr. and V.K. Pecharsky, International Journal of Refrigeration $\mathbf{3 1}$ (2008) 945.

3. A. Fujita and H. Yako, Scr. Mater. 67 (2012) 578.

4. V.K. Pecharsky and J.K.A. Gschneidner, Phys. Rev. Lett. 78 (1997) 4494.

5. J.L. Wang, S.J. Campbell, J.M. Cadogan et al., Appl. Phys. Lett. 98 (2011) 232509.

6. M.F. Md Din, J.L. Wang, R. Zeng et al., Intermetallics 36 (2013) 1-7.

7. A. Szytuła and J. Leciejewicz, Chapter 83 Magnetic properties of ternary intermetallic compounds of the RT2X2 type, in: Handbook on the Physics and Chemistry of Rare Earths, (K.A. Gschneidner, Jr. and E. LeRoy (Eds.)), Elsevier, Amsterdam (1989) 133.

8. J.L. Wang, L. Caron, S.J. Campbell et al., Phys. Rev. Lett. 110 (2013) 217211.

9. M.F. Md Din, J.L. Wang, S.J. Campbell et al., Appl. Phys. Lett. 104 (2014) 042401.

10. S.M. Yusuf, M. Halder, A.K. Rajarajan et al., J. Appl. Phys. 111 (2012) 093914.

11. J.L. Wang, S.J. Campbell, A.J. Studer et al., J. Appl. Phys. 104 (2008) 103911.

12. L.B. McCusker, R.B. Von Dreele, D.E. Cox et al., J. Appl. Crystallogr. 32 (1999) 36. 
13. S. Siek, A. Szytuła and J. Leciejewicz, Solid State Commun. 39 (1981) 863.

14. M.F.M. Din, J.L. Wang, S.J. Campbell et al., J. Phys. D: Appl. Phys. 46 (2013) 445002.

15. S. Di Napoli, A.M. Llois, G. Bihlmayer et al., Phys. Rev. B 75 (2007) 104406.

16. R. Zeng, J.L. Wang, L. Lu et al., J. Alloys Compd. 505 (2010) L38.

17. H. Feng-Xia, S. Bao-Gen, S. Ji-Rong et al., J. Phys.: Condens. Matter. 12 (2000) L691.

18. L. Caron, Z.Q. Ou, T.T. Nguyen et al., J. Magn. Magn. Mater. 321 (2009) 3559.

19. B. Li, W.J. Hu, X.G. Liu et al., Appl. Phys. Lett. 92 (2008) 242508.

20. X.X. Zhang, F.W. Wang and G.H. Wen, J. Phys.: Condens. Matter 13 (2001) L747.

21. V.K. Pecharsky and J.K.A. Gschneidner, J. Appl. Phys. 86 (1999) 565.
22. B. Ekkes, J. Phys. D: Appl. Phys. 38 (2005) R381.

23. K.A. Gschneidner Jr., V.K. Pecharsky and A.O. Tsokol, Reports on Progress in Physics 68 (2005) 1479.

24. M. Hofmann, S.J. Campbell and A.V.J. Edge, Phys. Rev. B 69 (2004) 174432.

25. I. Dincer, Y. Elerman, A. Elmali et al., J. Magn. Magn. Mater. 313 (2007) 342.

26. R. Welter, G. Venturini, D. Fruchart et al., J. Alloys. Compd. 191 (1993) 263.

27. R. Welter, G. Venturini, E. Ressouche et al., J. Alloys. Compd. 218 (1995) 204.

28. J.M.D. Coey, Solid State Sci. 7 (2005) 660.

29. T. Chatterji, J. Combet, B. Frick et al., J. Magn. Magn. Mater. 324 (2012) 1030.

30. K.A. Gschneidner Jr., Y. Mudryk and V.K. Pecharsky, Scr. Mater. 67 (2012) 572. 